\title{
Study on forward modeling of Submarine fault and slide based on FDM
}

\author{
Lei Chen, Bin Liu, Jie Song, Shucai Li, Xinji Xu, Ming Li \\ Research Center of Geotechnical and Structural Engineering \\ Shandong University, Jinan, China \\ clei667@163.com
}

\begin{abstract}
With the development of the seismic numerical modeling theory, a group of scholars do lots of seismic forward modeling studies. In this paper, wave equation finite difference method(FDM $)^{[1]}$ was used to build models of submarine fault and slide and forward seismic modeling. By studying character and imaging of wavefield, the method of recognizing submarine fault and slide was improved, meaningful and important geological information can be provided in to offshore engineering.
\end{abstract}

Keywords-forward modeling; finite difference method; submarine fault; submarine slide

\section{INTRODUCTION}

China has great potenation of marine resources. Offshore is the earliest and most frequent zone human developed and used marine resources. With offshore exploitation improving and economic developing, engineering construction scale increases gradually and building structure is more complex. It is important to ensure safety of the coastal cities and ocean engineering $^{[1]}$, such as harbor, sea-crossing bridge, undersea tunnel and offshore oil platform. Accurate detection of submarine fault and slide can effectively guarantee the safety of engineering project.

Seismic wave is a common way to detect sea geology and structure $^{[2-6]}$. Seismic forward modeling helps studying wavefield propagation regularity and improving explanation accuracy to detection data. FDM, difference equation replaces differential equation, is a most common way to achieve wavefield forward modeling. With the seismic numerical modeling technology ${ }^{[7]}$ developing, a group of scholars do many researches on complex geological models : By using high-order FDM wave equation, Chen $\mathrm{Wei}^{\left[{ }^{[8]}\right.}$ obtained relative geological structure under irregular surface, while satisfying requirements of stability; Wang Dawei ${ }^{[9]}$ studied seismic wavefield propagation regularity of land fault with different fillers; Ma Zaitian ${ }^{[10]}$ discussed the recognization method of natural gas hydrate(NGH) by forwarding marine seismic numerical modeling and physical modeling; Zhi-bin Sha ${ }^{[11]}$ optimized HF-OBS observation system and got the relationship between $\mathrm{P}$-wave and $\mathrm{S}$-wave of hydrate by combining travel time inversions of $\mathrm{P}$-wave and $\mathrm{S}$-wave. Considering shear waves are absorbed in water, we used twodimensional acoustic wave equation to forward modeling based on FDM. The article studied the propagation and imagining regularity of submarine fault and slide to provide guidance for improving recognition method.

\section{THEORY}

\section{A. Acoustic Equation Derivation}

In acoustic equation, the properties of media are determined by two parameters: propagation speed and density .The acoustic wavefield is described by velocity vector field of displacement and pressure field. The primitive equation $^{[12]}$ is to be written as:

$$
\left\{\begin{array}{l}
\frac{\partial u_{1}}{\partial t}=\frac{1}{\rho} \frac{\partial p}{\partial x_{1}} \\
\frac{\partial u_{3}}{\partial t}=\frac{1}{\rho} \frac{\partial p}{\partial x_{3}} \\
\frac{\partial p}{\partial t}=\rho v^{2}\left(\frac{\partial u_{1}}{\partial x_{1}}+\frac{\partial u_{3}}{\partial x_{3}}\right)
\end{array}\right.
$$

Take differential to equation above, we have:

$$
\left\{\begin{array}{l}
\frac{\partial^{2} u_{1}}{\partial t \partial x_{1}}=\frac{\partial(1 / \rho)}{\partial x_{1}} \frac{\partial p}{\partial x_{1}}+\frac{1}{\rho} \frac{\partial^{2} p}{\partial x_{1}^{2}} \\
\frac{\partial^{2} u_{3}}{\partial t \partial x_{3}}=\frac{\partial(1 / \rho)}{\partial x_{3}} \frac{\partial p}{\partial x_{3}}+\frac{1}{\rho} \frac{\partial^{2} p}{\partial x_{3}^{2}} \\
\frac{\partial^{2} p}{\partial t^{2}}=\rho v^{2}\left(\frac{\partial^{2} u_{1}}{\partial t \partial x_{1}}+\frac{\partial^{2} u_{3}}{\partial t \partial x_{3}}\right)
\end{array}\right.
$$

Solve equations and get equation as followed ${ }^{[12]}$ :.

$$
\frac{\partial^{2} p}{\partial t^{2}}=v^{2}\left(\frac{\partial^{2} p}{\partial x_{1}^{2}}+\frac{\partial^{2} p}{\partial x_{3}^{2}}\right)+\rho v^{2}\left(\frac{\partial(1 / \rho)}{\partial x_{1}} \frac{\partial p}{\partial x_{1}}+\frac{\partial(1 / \rho)}{\partial x_{3}} \frac{\partial p}{\partial x_{3}}\right)
$$

\section{B. Decomposition Of Finite Difference Method}

Two dimensional acoustic equation ${ }^{[12]}$ was simplified as:

$$
\frac{\partial^{2} p}{\partial t^{2}}=v^{2}\left(\frac{\partial^{2} p}{\partial x_{1}^{2}}+\frac{\partial^{2} p}{\partial x_{3}^{2}}\right)
$$


Expansion second order partial derivatives equation by Taylor, we have:

$$
\left\{\begin{aligned}
p_{i+1, j}^{n}= & p_{i, j}^{n}+\Delta x\left(\frac{\partial p}{\partial x}\right)_{i, j}^{n}+\frac{1}{2} \Delta x^{2}\left(\frac{\partial^{2} p}{\partial x^{2}}\right)_{i, j}^{n} \\
& +\frac{1}{6} \Delta x^{3}\left(\frac{\partial^{3} p}{\partial x^{3}}\right)_{i, j}^{n}+\cdots+O\left(\Delta x^{4}\right) \\
p_{i-1, j}^{n}= & p_{i, j}^{n}-\Delta x\left(\frac{\partial p}{\partial x}\right)_{i, j}^{n}+\frac{1}{2} \Delta x^{2}\left(\frac{\partial^{2} p}{\partial x^{2}}\right)_{i, j}^{n} \\
& -\frac{1}{6} \Delta x^{3}\left(\frac{\partial^{3} p}{\partial x^{3}}\right)_{i, j}^{n}+\cdots+O\left(\Delta x^{4}\right)
\end{aligned}\right.
$$

Decompose the equations[12] set with FDM,we have:

$$
\left\{\begin{array}{l}
\frac{\partial^{2} p}{\partial x_{1}^{2}}=\frac{p_{i+m, j}^{n}-2 p_{i, j}^{n}+p_{i-m, j}^{n}}{\Delta x_{1}^{2}} \\
\frac{\partial^{2} p}{\partial x_{3}^{2}}=\frac{p_{i+m, j}^{n}-2 p_{i, j}^{n}+p_{i-m, j}^{n}}{\Delta x_{3}^{2}} \\
\frac{\partial^{2} p}{\partial t^{2}}=v^{2}\left(\frac{\partial^{2} p}{\partial x_{1}^{2}}+\frac{\partial^{2} p}{\partial x_{3}^{2}}\right)
\end{array}\right.
$$

Then we get the equation of high order finite difference ${ }^{[12]}$ :

$$
\frac{\partial^{2} p}{\partial t^{2}}=v^{2} \sum_{m=1}^{M} A_{m}\left(\frac{p_{i+m, j}^{n}-2 p_{i, j}^{n}+p_{i-m, j}^{n}}{\Delta x_{1}^{2}}+\frac{p_{i, j+m}^{n}-2 p_{i, j}^{n}+p_{i, j-m}^{n}}{\Delta x_{3}^{2}}\right)
$$

\section{III.EXAMPLES}

We assumed strata are isotropy media and studied wavefield propagation regularity of submarine fault and slide. We built models by Tesseral-2D. Considering actual offshore detection needs, We set that length of model is $500 \mathrm{~m}$ and depth of model is $300 \mathrm{~m}$. Ricker was used as source with $200 \mathrm{~Hz}$, sample interval was $0.5 \mathrm{~ms}$. Stimulate seismic wave in several places and record vibration signal by many receivers. The observation system is arranged as Fig.1 shows.

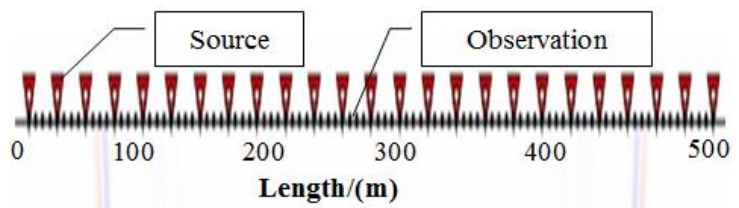

Fig.1 Layout schematic diagram of observation system

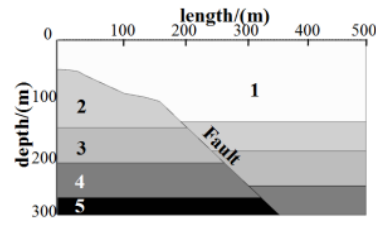

Submarine fault A

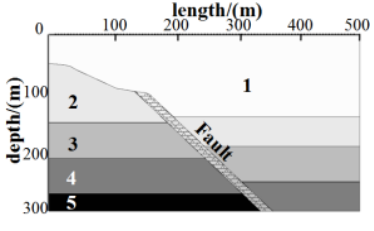

Submarine fault B
Fig.2 Stratigraphic models of submarine fault

\section{Forward Modeling Of Submarine Fault}

Single fault was studied, as Fig.2 shows, geological models were built in two forms by changing fracture thickness, one is model with $20 \mathrm{~m}$ fracture zone, another is model without fracture. Rock parameters were designed(TABLE I.) to ensure rock strata have different waveimpedance parameters.

Diffraction generated when seismic wave passing by breaking points. What's more, transmitted and reflected waves generated when waves meeting boundary surface.

As Fig.3 shows, seismic wave drove across the fault without fracture zone and then spread downward fast in model A. Affected by fracture zone of fault in model B, diffraction generated when seismic wave meeting two breaking points of fault, what's more, there are more than one transmitted and reflected waves generating on two sides of fault zone. The time wave spread downward in model B is later than the time in model A.

In model B, as Fig.4 shows, wave spread with a low speed in fracture zone than in intact rock. In addition, multiples generated in fracture zone, seismic wavefield interfered and superimposed.

TABLE I. ROCK PARAMETERS

\begin{tabular}{cccc}
\hline No & Vp $(\mathrm{m} / \mathrm{s})$ & $\mathrm{Vs}(\mathrm{m} / \mathrm{s})$ & $\rho_{\left(\mathrm{kg} / \mathrm{m}^{3}\right)}$ \\
\hline 1 & 1500 & 0.25 & 1000 \\
2 & 2200 & 1000 & 1600 \\
3 & 2500 & 1000 & 1700 \\
4 & 3500 & 2000 & 2200 \\
5 & 5500 & 3000 & 2600 \\
fault & 2000 & 1000 & 2000 \\
\hline
\end{tabular}

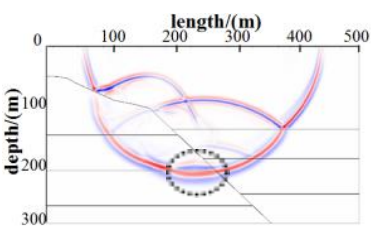

Submarine fault A

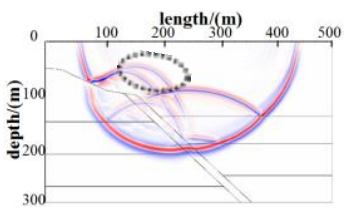

Submarine fault B
Fig.3 Wavefield snapshots of 0.128 s

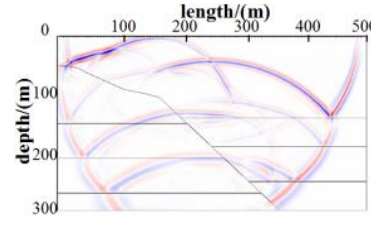

Submarine fault A

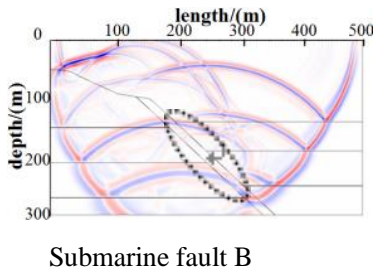

Fig.4 Wavefield snapshots of 0.160 s 
According to gathers (Fig.5), seismic wavefield of model A without fracture zone is simple, boundaries can be recognized easily than model $B$. Choose part gathers of models, it's easy to find direct wave and reflections. Compare records and we find the difference that reflections generated on two sides of fault in model B. Because two boundaries have different reflection coefficient, reflected waves from two boundaries have different amplitude: the first reflected

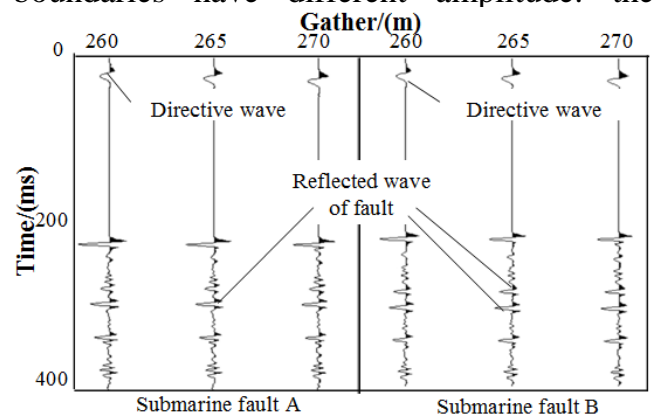

Fig.5 Shot gathers simulated form model A\&B

wave amplitude less than the second reflected wave amplitude.

Raw data were processed by many steps: muting, trace gathering, NMO, stacking, post-stack kirchhoff migration. Then we got migration in time domain.

As Fig. 6 and Fig.7 shows, strata thickness and distribution can be recognized well. because existence of fracture zone(low speed region), seismic wave generated more multiple reflections and interference in model B. Affected by this it, seismic wave of strata boundaries under inclined fault responded bad. The right phase axis of fault's footwall is not clear, what's more, the real record is accompanied with false anomaly. Meanwhile, the phase axis on the left of fault is clear since the wave entering intact rock from broken rock. On the contrary, the phase axis is blurring when the wave entering broken rock from intact rock. In addition, because seismic wave's propagation is based on velocity and density of rock, so the interface phase axis is discontinuous and displays in ladder shape.

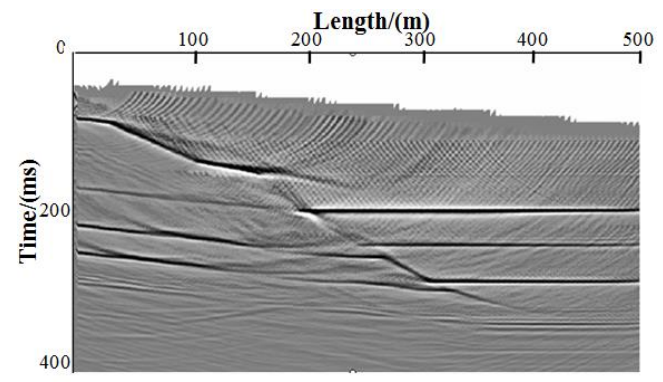

Fig.6 Migration results of model A in time domain

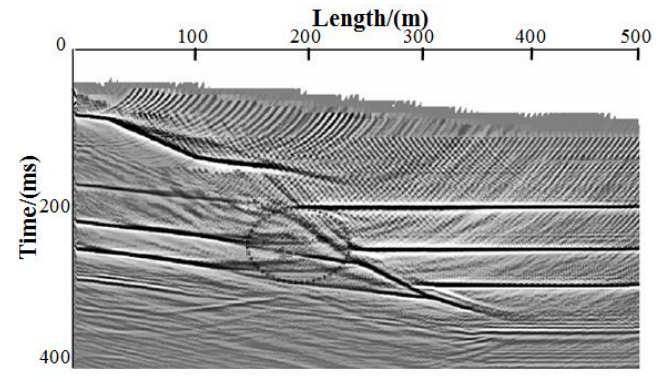

Fig.7 Migration results of model B in time domain

\section{Forward Modeling Of Submarine Slide}

Single slide as the main object was studied, and geological model was built as Fig.8 shows.

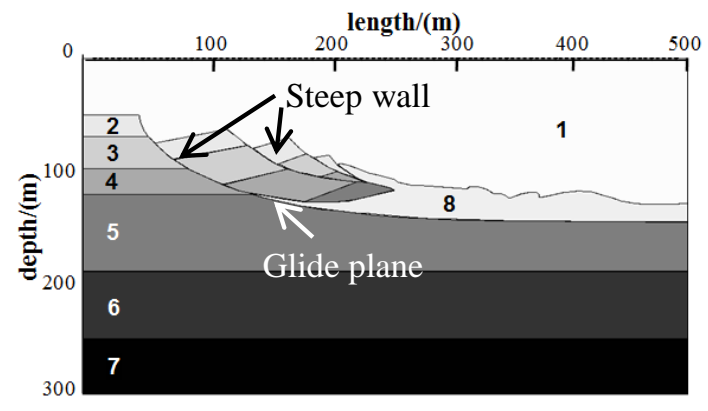

Fig.8 Stratigraphic model of submarine slide

TABLE II. ROCK PARAMETERS

\begin{tabular}{cccc}
\hline No & $\mathrm{Vp}(\mathrm{m} / \mathrm{s})$ & $\mathrm{Vs}(\mathrm{m} / \mathrm{s})$ & $\rho\left(\mathrm{kg} / \mathrm{m}^{3}\right)$ \\
\hline 1 & 1500 & 0.25 & 1000 \\
2 & 1800 & 1050 & 1994 \\
3 & 2200 & 1270 & 2086 \\
4 & 2800 & 1618 & 2200 \\
5 & 3500 & 2020 & 2275 \\
6 & 4700 & 2723 & 2455 \\
7 & 5500 & 3205 & 2575 \\
8 & 1700 & 1000 & 1986 \\
\hline
\end{tabular}

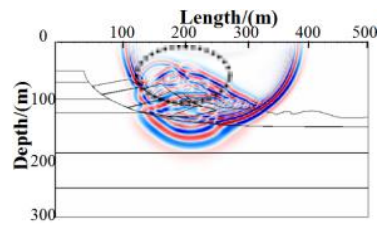

$\mathrm{T}=0.096 \mathrm{~s}$

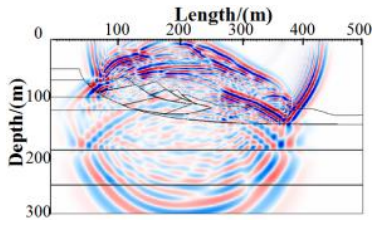

$\mathrm{T}=0.128 \mathrm{~s}$
Fig.9 Wavefield snapshots

Rock parameters(TABLE II) was designed to ensure strata have different waveimpedance parameters.

Diffraction, transmitted and reflected waves created when the seismic wave passing through the model. As Fig.9 shows, Diffraction, transmitted and reflected waves generated when waves meeting glide plane, and multiple generated in body of 
landslide. seismic waves interfered and superimposed. Internal reflection was messy. Seismic wave amplitude attenuated obviously when passing by landslide.

Choose part of gathers and study it. As Fig.10 shows, it's easy to find direct wave. But affected by many reflections nearby the interface of landslide, phase axis superimposed on another. which made it hard to recognize the reflected wave. Meanwhile, the amplitude of wave reached the maximum when first meeting landslide. When waves passing by landslide, the amplitude of seismic wave decreased rapidly, which made it hard to recognize phase axis of horizontal strata interface under landslide.

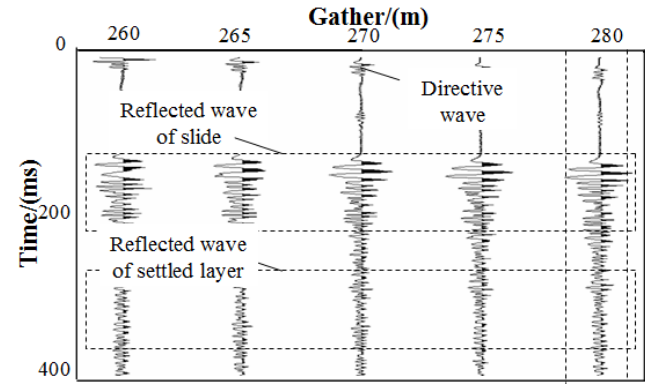

Fig.10 Shot gathers simulated form model

Raw data were processed by many steps: muting, trace gathering, NMO, stacking, post-stack kirchhoff migration.

Then we got migration in time domain(Fig.11).

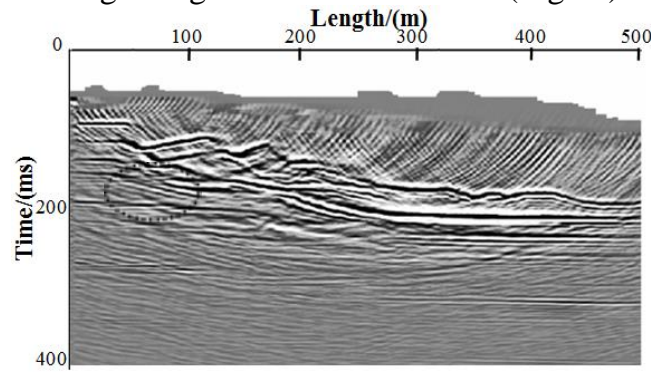

Fig.11 Migration results of slide in time domain

As Fig.11 shows, the scale and shape of landslide can be recognized approximately from migration in Fig.11, but because slip planes and the steep walls are discontinuous and complex, the reflected wave phase axis of landslide is discontinuous. Affected by steep walls and breaking points, mutation region exists in the phase axis of gathers. Contemporary, seismic waves reflected, diffracted and transmitted at a angle in landslide, wave affected each other, seismic waves interfered and superimposed. Which made amplitude of wave reduced fast when passing by landslide, and made it hard to recognize horizontal strata under landslide. What's more, some reflection phase axis of the horizontal interface migrated with a distance and rotated with an angle.

\section{CONCLUSION}

In this paper, FDM was used to simulate wave propagation process effectively. By studying wave propagation characters and migration, recognize method of submarine fault and slide can be improved:

In seismic profile, fault (scale and size) can be recognized by regular dislocation, reflection intensity and displacement of phase axis on two sides of fault. If reflected phase axis is continues and clear, we can deduce that fault plane is complete If reflected phase axis is discontinues and blurry, we can deduce that it is likely to exist fracture zone, and extra work should be done to study the scale of influenced region.

Landslide can be judged by the random permutation and combination of interface reflected phase axis, mainly recognized by phase axis of steep wall. Steep wall usually intersects with horizontal interface at an big angle. The main slide of landslide is complete and continues. What's more, affected by sliding action, phase axis of landslide root area displayed in a shape of bow with several discontinues bumps.

\section{REFERENCES}

[1] Kelly K R, Ward R W, Treitel S, et al. 1976, Synthetic seismograms: a finite-difference approach[J]. Geophysics, 41(1): 2-27.

[2] WANG Z C, DENG Q D, CHAO H T, et al. 2006, Shallow - Depth Acoustic Reflection Profiling Studies on the Active Penglai - Weihai Fault Zone Offshore of the Northern Shandong Peninsula[J]. Chinese Journal of Geophysics, 49(4): 986-995.

[3] Wang K, Zheng Y, Wang S. 1999, Application of acoustic technology to seismo-stratigraphy surveying in offshore[J]. Marine Geology and Quaternary Geology, 19: 97-102.

[4] Wu Z, Jin X, Li J. 2002, Seismic stratigraphic interpretation of highresolution seismic profiles between Yangtze estuary and Okinawa trough[J]. Marine Geology and Quaternary Geology, 22(2): 9-20.

[5] Liu J P, Milliman J D, Gao S, et al. 2004, Holocene development of the Yellow River's subaqueous delta, North Yellow Sea[J]. Marine geology, 209(1): 45-67.

[6] Liu B, Ding J, Pei Y. 2005, Marine geophysical survey techniques and their applications to offshore engineering[J]. Advances in Marine Science, 23(3): 374.

[7] Pei Z L, Mou Y G. 2004, Numerical simulation of seismic wave propagation[J]. Progress in Geophysics (in Chinese), 19(4): 933-941。

[8] Chen Wei, 2005, Numerical modeling of 2-D seismic wavefield under ragged surface[J],PEG, 28(1):25 31.

[9] Dawei Wang. 2011, The research of elastodynamics of the earthquake wave in crush zone [D]. Ocean University of China.

[10] Ma Z, Geng J, Dong L, et al. 2002, Seismic recognition studies on marine gas hydrate[J]. Marine Geology and Quaternary Geology, 22(1): 1-8.

[11] Sha Zhibin; Zheng Tao; Zhang Guangxue;2014, An optimal design of a high-frequency ocean bottom seismometer(HF-OBS) and its application to the natural gas hydrate exploration in the south china sea[J],Natural Gas Industry,34(7): 136-142.

[12] Lu Jimeng. The principle of seismic exploration[J], China University Of Petroleum Press, 1993: 291-357. 